\title{
Drug Use and High-Risk Sexual Behaviors of Women at a Drop-In Center in Mazandaran Province, Iran, 2014
}

\author{
Hassan Taghizadeh ${ }^{1}$; Fatemeh Taghizadeh ${ }^{2,{ }^{*}}$; Mohammad Fathi ${ }^{3}$; Parisa Reihani ${ }^{4}$; Nasrin \\ Shirdel ${ }^{5}$; Seyede Mohaddese Rezaee ${ }^{6}$ \\ ${ }^{1}$ Department of Anesthesiology, Shahid Beheshti University of Medical Sciences, Tehran, IR Iran \\ ${ }^{2}$ Psychiatry and Behavioral Science Research Center, Addiction Institute AND Department of Mental Health, Public Health Center, Mazandaran University of Medical Sciences, Sari, \\ IR Iran \\ ${ }^{3}$ Department of Anesthesiology, Shahid Beheshti University of Medical Sciences, Tehran, IR Iran \\ ${ }_{5}^{4}$ Department of Psychology, Educational Organization of Mazandaran, Sari, IR Iran \\ ${ }^{5}$ Departmentin Center, Sari, IR Iran \\ ${ }^{6}$ Department of Mental Health, Public Health Center, Sari, IR Iran \\ ${ }^{*}$ Corresponding author: Fatemeh Taghizadeh, Addiction Institute, Psychiatry and Behavioral Science Research Center, Department of Mental Health, Public Health Center, \\ Mazandaran University of Medical Sciences, P. O. Box: 4816711447, Sari, IR Iran. Tel/Fax:+98-1512298912, E-mail: tag.faty@yahoo.com
}

Received: June 29, 2014; Revised: July 15, 2014; Accepted: November 24, 2014

\begin{abstract}
Background: Female drug users are more likely to transmit human immunodeficiency virus (HIV) to their sexual partners. Little is known about HIV, sexually transmitted diseases (STDs), cervicitis, and drug abuse among female sex workers in Iran.

Objectives:Therefore, this study was conducted at a drop-in center(DIC) in Iran to investigate the prevalence of HIV associated risk factors, the prevalence of drug use, high-risk sexual behaviors, and the relationship between the associated factors in women.

Patients and Methods: This quantitative cross-sectional study was conducted on 190 female sex workers(SW) in a DIC in Sari, Mazandaran, Northern Iran, in January and February 2014. The study sample was selected through census sampling. In the end, 190 female SWs referring to the DIC participated in our study. There was no limitation in sampling. The self-administered questionnaire was completed via an interview.

Results: The results showed that $39 \%$ of the female SWs were less than 30 years old and $64 \%$ had elementary school education. In addition, $59 \%$ of the participants took some type of illegal drugs and $1.1 \%$ of them were reportedly injecting drug users. Moreover, $43 \%$ of them had substance dependent husbands, and 39\% were reportedly regular condom users. They had 1-10 sexual partners on average per week. The overall prevalence of HIV infection was $4 \%$. A significant relationship was found between the type of drugs used and factors such as having a substance dependent husband, use of condom during the last sexual contact, regular condom use, and the number of sexual acts per week. A significant correlation exists between using psychiatric drugs and factors like regular condom use, education, cervicitis, and the number of sexual conducts per week.

Conclusions: Female sex workers often engage in sex for financial reasons and are at high risk of drug abuse, HIV, and cervicitis. In addition, the rate of cervicitis among females with high-risk sexual behavior is considerable in Mazandaran, Iran. Therefore, the state authorities should provide sex workers with health care services and help them acquire a good job to support their life.
\end{abstract}

Keywords: Uterine Cervicitis; HIV; Sex Workers; Drug Abuse

\section{Background}

Drug use puts individuals at greater risk for sexually transmitted diseases (STDs), HIV, and vaginal infections (1-3) (that in turn increases the risk of HIV transmission) (4). Thus, the involved women transmit HIV/AIDS to their sexual partners (5). Drug users, comparing with nondrug users, engage in high risk behaviors (e.g. aggression and shared use of needles/syringes). Several studies have shown that some users try to reduce the rate of high-risk sexual behaviors $(6,7)$.

Some of HIV-infected injecting drug users regularly use condoms to protect their partners. This conduct is called informed altruism (8). However, some studies have shown that HIV-positive drug users show resistance to reduce high-risk behaviors. This may be due to social pressure, poverty, unemployment, low educational level, substance dependence, and clients' preferences (9). Little investigation has been conducted on the effect of HIVpositive awareness on the modification of risk behaviors among female HIV-positive drug-users.

Sexually transmitted infections (STI) are among the main causes of mortality in developing countries and are mostly observed in those with multiple sex partners (10). Presumably, 340 million new cases of STI are reported every year among 15 - 49 years age group (11). Some people are infected for a long period of time without any symptoms, so they are not aware of their disease may spread it (12). The prevalence of STDs increases among females with illegal social behaviors because of their high num-

Copyright (C) 2015, Mazandaran University of Medical Sciences. This is an open-access article distributed under the terms of the Creative Commons Attribution-NonCommercial 4.0 International License (http://creativecommons.org/licenses/by-nc/4.0/) which permits copy and redistribute the material just in noncommercial usages, provided the original work is properly cited. 
Taghizadeh H et al.

ber of sexual partners and high rate of risky behavior. These women are important sources of HIV and STDs transmission to their sexual partners (13). The prevalence of HIV and STDs in high risk groups differs in various areas and female sex workers (SW) around the world $(14,15)$. HIV has the highest prevalence in subgroups such as SWs who constantly change their sexual partners and engage in unprotected sex (16). Health care services for SWs such as education, condom use, and effective treatment of HIV and STIs, and structured interventions, reduce the risk of HIV and STD transmission (17). The present investigation studied the prevalence of substance use, STDs, change in sexual partners, and multiple sexual partners in SWs. The present study showed the prevalence of drug use or risky sexual behaviors, and the relationship between substance use and multiple sexual partners. It also shows the prevalence of drug use or risky sexual behaviors and the relationship between them in the women who referred to a female-specific DIC in Mazandaran Province, Iran, 2014.

\subsection{Female-Specific Drop-in Center}

This center was founded in Mazandaran Province, Sari, Iran, in 2005 with the authorization of the Ministry of Health and Medical Education. Its goal was to control HIV/ AIDS and STDs among female SWs, and other vulnerable and substance dependent women. It enhances the safety and security of vulnerable women and provides support, training, and health services for female injecting drug users and SWs. At present, there are DICs in 15 provinces of Iran. About 190 vulnerable women visit the female-specific DIC in Sari, Iran, for receiving education as well as doctor and midwifery examination every month. This center is supervised by Sari Health Center.

Hepatitis B Virus (HBV) test and rapid HIV test are performed on all women on their first visit and free condoms are provided for them. DIC in Sari conducts advocacy workshops for clients on HIV, condom use, and negotiation skills for condom use in women, sexual health, healthy drug injection, and STDs on a regular basis. A Pap smear test and vaginal examination for the diagnosis of cervicitis are performed at least once a year. Warm meals are distributed once a week in the center. Currently, 19 substance dependents are being treated with methadone while a training-workshop on tailoring is being held to financially support the clients. A number of these cases were referred to support organizations.

\section{Objectives}

Female drug users are more likely to transmit human immunodeficiency virus (HIV) to their sexual partners. Little is known about problems such as HIV, sexually transmitted diseases (STDs), cervicitis, and drug abuse among female sex workers in Iran. Therefore, this study was conducted to investigate the prevalence of drug use and HIV associated risk factors; high-risk sexual behav- iors; and the relationship between the associated factors in women at a drop-in center (DIC) in Iran.

\section{Materials and Methods}

This cross-sectional descriptive study was conducted in Sari, North of Iran, in January and February 2014. All 190 female SWs in the DIC participated in our study. The survey was approved by ethic committee of mazandaran University of Medical Sciences. The samples were selected through census sampling. In addition, there were no limitations in the sampling. The participants were given detailed information about the objectives and procedures of the study and an informed written consent was obtained from each of them. The self-administered questionnaire was completed via an interview. Their information regarding age, educational level, sexual activity in exchange for money, marital status, occupation, frequency of sex, condom use, number of partners per week, and injection drug use were collected. They also provided information with regard to their spouse's drug use, sex-related behavior, HIV tests, frequency and type of marriage, and paying sex partners. Data analysis was performed using SPSS for Windows (version 15; SPSS Inc., Chicago, IL, USA). Descriptive statistics were calculated as frequency distribution tables, mean, and standard deviation. Pearson correlation, Spearman rank correlation coefficient, contingency correlation coefficient, Cohen kappa coefficient, phi coefficient, and Cramer V were used to study correlations.

\section{Results}

The participants of this study were between 19 and 54 years old; the median age range was 33 years. Among them, $1.1 \%$ was below 20 years of age, $38 \%$ were 20 - 30 years of age, 33\% of them 31 - 40 years, and 33\% over 40 years. In addition, $24 \%$ of the participants were illiterate. Moreover, $59 \%$ of the participants were drug users, among them $16 \%$ were addicted to Iranian crack or heroin, $16 \%$ to opium and methamphetamine, $25 \%$ to methamphetamine, and 13\% to methamphetamine and alcohol, and $1.1 \%$ were intravenous drug users. The rate of participants with substance dependent husbands was $43 \%$, and $84 \%$ had had a recent Pap test and $61 \%$ had candidiasis. Number of sexual acts per day was various from 1 to 3 , and $62 \%$ of them regularly used condoms. The cost of every sexual act ranged from 2 to 10 USD. Their monthly income ranged from 10 to 700 USD and the average was 201 USD. Vaginal exam showed that $44 \%$ had cervicitis. Furthermore, $48 \%$ consumed psychiatric drugs. Rapid HIV test showed a $4 \%$ HIV infection rate in those who referred to behavioral counseling centers (Tables 1-3).

Table 4 demonstrates a significant relationship between being a SW and the type of drugs used. A significant relationship was observed between the type of drugs used and factors such as having a substance dependent husband, sexual intercourse methods, use of condom during 
Taghizadeh $\mathrm{H}$ et al.

the last sexual contact, consistent condom use, and number of sexual acts performed per week. A significant correlation was also observed between the use of psychiatric drugs and regular condom use, education, cervicitis, and the number of sexual acts per week. Furthermore, there was a significant relationship between the type of sexual act, and regular condom use as well as condom use in the last sexual contact.

The relationship between substance dependency and variables like educational level, psychiatric drugs, number of sexual acts and per week sexual partners was significant. A significant relationship was also observed between the type of drug used and factors such as being a SW, having a substance dependent husband, and the number of sex partners. Moreover, a significant correlation exists between regular condom use and educational level, cervicitis, as well as the number of sexual contacts per week. Finally, regular use of condom had a significant relationship with addiction, type of drugs, type of psychiatric medications, and the sex methods used.

A significant relationship was observed among educational level and cervicitis, age, money taken per sexual act, duration of working as a SW, use of psychiatric drugs, and addiction. Moreover, cervicitis had a significant relationship with number of sexual acts and sexual partners per week. The relationship between age and money taken for each sexual act was also significant. In addition, there was a significant relationship between the number of sexual contacts per week and the use of psychiatric drugs. There was also a significant relationship between the number of sexual partners and having a substance dependent husband. A significant relationship was also observed between addiction and the number of sexual acts per day and number of sexual partners.

Table 1. Sociodemographic Characteristics and Sexual Behavior Reported by Clients ${ }^{\text {a }}$

\begin{tabular}{|c|c|c|c|c|c|c|c|c|}
\hline \multirow[t]{2}{*}{ Variable } & \multicolumn{2}{|c|}{ Age, $y$} & \multirow{2}{*}{$\begin{array}{l}\text { Number of } \\
\text { Children }\end{array}$} & \multirow{2}{*}{$\begin{array}{l}\text { Number of } \\
\text { Sex Contacts } \\
\text { Per Day }\end{array}$} & \multirow{2}{*}{$\begin{array}{l}\text { Number of } \\
\text { Sex Contacts } \\
\text { Per Week }\end{array}$} & \multirow{2}{*}{$\begin{array}{c}\text { Money Taken } \\
\text { Per Sexual } \\
\text { Act }\end{array}$} & \multirow{2}{*}{$\begin{array}{c}\text { Number of } \\
\text { Sex Partners } \\
\text { Per Week }\end{array}$} & \multirow{2}{*}{$\begin{array}{c}\text { Duration } \\
\text { of Sexual } \\
\text { Work, } y\end{array}$} \\
\hline & Sex worker & Others & & & & & & \\
\hline Mean & 33.4 & 40.9 & 2 & 1.3 & 4.6 & 11.8 & 3.5 & 8.3 \\
\hline Median & 33.0 & 40.0 & 2.0 & 1.0 & 4.0 & 10.0 & 3.0 & 6.0 \\
\hline Mode & 26.0 & 29.0 & 0.00 & 1.0 & 2.0 & 10.0 & 2.0 & 3.0 \\
\hline Standard deviation & 09.1 & 09.3 & 0.00 & 0.51 & 3.2 & 5.9 & 2.1 & 6.4 \\
\hline Minimum & 19.0 & 27.0 & 0.00 & 1.0 & 1.0 & 5.0 & 1.0 & 1.0 \\
\hline Maximum & 54.0 & 56.0 & 7.0 & 3.0 & 15.0 & 30.0 & 10.0 & 30.0 \\
\hline Valid data & 155 & 29 & 184 & 58 & 146 & 146 & 142 & 136 \\
\hline
\end{tabular}

a Sample size is equal to 184 .

\begin{tabular}{|c|c|c|c|c|}
\hline \multirow[t]{2}{*}{ Variable } & \multirow[t]{2}{*}{ Overall Number } & \multirow[t]{2}{*}{ No. (\%) } & \multicolumn{2}{|c|}{ No. (\%) } \\
\hline & & & Sex Worker & Non-Sex Worker \\
\hline Sex worker & 184 & $154(84.70)$ & & \\
\hline Marital status & 184 & & & \\
\hline Single & & $25(13.59)$ & $24(15.48)$ & $1(3.45)$ \\
\hline Married & & $94(51.9)$ & $76(49.03)$ & $62.1(62.07)$ \\
\hline Divorced & & $42(22.83)$ & $39(25.16)$ & $3(10.34)$ \\
\hline Widow & & $16(80.70)$ & $9(5.81)$ & $7(29.14)$ \\
\hline Concubine & & $7(3.80)$ & $7(4.52)$ & $0(0)$ \\
\hline Personal home & 183 & $73(39.89)$ & $59(38.3)$ & $14(48.3)$ \\
\hline Protected by support organizations & 183 & $47(25.68)$ & & \\
\hline Welfare office & & $8(4.37)$ & $6(3.9)$ & $2(7.1)$ \\
\hline Imam Khomeini Relief Foundation & & $39(21.31)$ & $29(18.71)$ & $10(35.71)$ \\
\hline Educational status & 183 & & & \\
\hline Illiterate & & $43(23.50)$ & $35(22.9)$ & $8(27.6)$ \\
\hline Primary and guidance school education & & $74(40.44)$ & $59(38.6)$ & $15(51.7)$ \\
\hline High school education and diploma & & $62(33.88)$ & $56(36.6)$ & $6(20.7)$ \\
\hline High educational level & & $3(2)$ & $2(1.5)$ & $0(0)$ \\
\hline Job & 184 & $37(20.1)$ & $29(18.7)$ & $8(27.6)$ \\
\hline
\end{tabular}


Taghizadeh Het al.

\begin{tabular}{|c|c|c|c|c|}
\hline \multirow[t]{2}{*}{ Variable } & \multirow[t]{2}{*}{ Total Number } & \multirow[t]{2}{*}{ No. (\%) } & \multicolumn{2}{|c|}{ No. (\%) } \\
\hline & & & Sex Worker & Non-Sex Worker \\
\hline $\begin{array}{l}\text { Sexual intercourse methods } \\
\end{array}$ & 146 & & & \\
\hline Vaginal & & $78(54.79)$ & $80(54.8)$ & \\
\hline Vaginal and anal & & $33(22.60)$ & $35(23.9)$ & \\
\hline Vaginal, anal and oral & & $26(19.18)$ & $26(17.8)$ & \\
\hline Oral & & $5(3.42)$ & $5(3.4)$ & \\
\hline STD & 117 & & & \\
\hline Gonorrhea & & $1(0.5)$ & $1(1)$ & \\
\hline Candidiasis & & $113(61.4)$ & $99(96.1)$ & \\
\hline Other STD & & $3(1.6)$ & $3(2.9)$ & \\
\hline HIV testing & 183 & $182(99.45)$ & $153(99.4)$ & $29(100)$ \\
\hline Cervicitis & 174 & $77(44.25)$ & $68(46.3)$ & $9(33.3)$ \\
\hline Information about HIV and HBV & 181 & $181(100)$ & $153(98.7)$ & \\
\hline Pap smear test & 184 & $154(83.70)$ & $130(83.87)$ & $24(82.76)$ \\
\hline Regular condom use & 149 & $93(62.42)$ & $93(62.4)$ & \\
\hline Condom use in the last sexual contact & 149 & $117(78.52)$ & $117(78.5)$ & \\
\hline
\end{tabular}

a Abbreviations: STD, Sexually transmitted diseases; HIV, Human immunodeficiency virus; HBV, Hepatitis B virus.

b Sample size is equal to 184 .

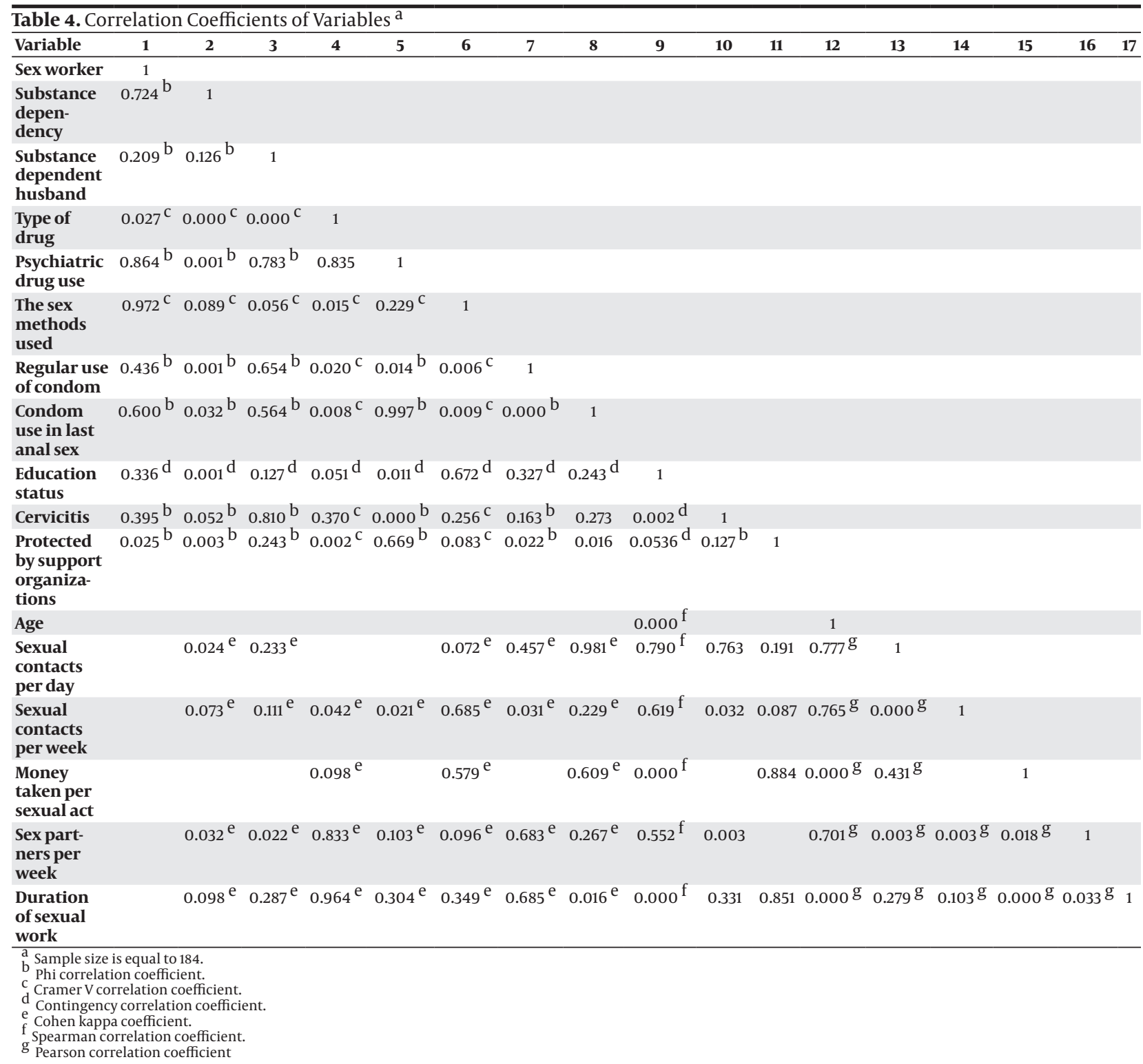




\section{Discussion}

Routine monitoring shows that among female SWs who contacted health services, $86 \%$ had visited the project STD clinics at least once, while about $75 \%$ benefited from clinical services every month. In a study performed on female SWs to diagnose cervical infections, the social, geographic, behavioral, clinical, and biological factors had a relationship with steady partners, symptoms of cervical infections, trained and experienced technicians, and laboratory tests such as the Pap smear (17). In the present study, gonorrhea was observed in $0.5 \%$ and cervicitis in $44 \%$ of females with illegal sexual behaviors. Moreover, there is a significant correlation between regular condom use and factors such as educational level, cervicitis, and the number of sexual contacts per week. A significant relationship was also observed between condom use in their last sexual contact and the duration of sex work. Educated young women are less vulnerable to intimate partner violence -a risk factor for HIV infection- compared to uneducated women, and could leave more easily violent relationships. Furthermore, they have a wide knowledge of contraceptive methods, and thus, can avoid many of the risk factors for HIV infection. Education can help reduce violence against women, promote gender equitable attitudes among men, and reduce STDs and cervicitis. This education includes promoting condom use and reduction in individuals' number of sexual partners.

In one study in Iran, the prevalence of HIV infection was 4.7\%; the most prevalent sexually transmitted infection was herpes simplex type 2 (9.7\%), followed by chlamydia (9\%), and gonorrhea (1.43\%). Moreover, 69.9\% of female SWs reported a history of drug abuse, of them $16.4 \%$ had a history of injecting drug use. In addition, $79.8 \%$ of the participants stated that their incentive to have sex in the previous month was financial. During this period, $24.4 \%$ of participants had unprotected sex and 30.1\% of them sometimes used a condom, $4.7 \%$ almost every time, and $40.6 \%$ for all instances of vaginal intercourse (18). Another study showed that $19 \%$ of female SWs reported at least one occasion of unprotected sex with an injecting drug user in the past one month (19). Fahimfar et al. (20) showed that most of the studied 442 SWs (36.2\%) were 25 - 34 years old, and 14.3\% of them illiterate and 31\% unemployed. The most prevalent risk factors were risky sexual behavior (27.1\%) and non-injecting drug use (23.2\%). In the present study, the age of the participants ranged from 19 to 54 years, and $1.1 \%$ of substance dependents were injecting drug users. In the study by Sajadi et al. (21) the prevalence of HIV infection (95\% CI) was 4.5\% (2.4 to 8.3), overall, $4.8 \%$ (2.2 to 9.8) among those who had reported a history of drug use and $11.2 \%$ (5.4 to 21.5 ) a history of injection drug use. Another study in Iran reported that the prevalence of condom use in the last sexual act with paying clients and non-paying partners were $57.1 \%$ and $36.3 \%$, respectively (22). In this study, the rate of regular condom use was 39\%. In another study in Iran, the estimate of un- protected sex in the last sexual act was $35.8 \%$, constant injection of drugs $37.6 \%$, sexually transmitted disease symptoms $82.1 \%$, and not testing for HIV in the last year $64.0 \%$ (23). All participants of the current study had been tested for HIV and $4 \%$ of them were HIV positive. In one study, bivariate analyses showed significant positive association between Iranian heroin crack use and number of partners regardless of type of sexual activity. Those who used Iranian crack had more partners for all sexual activities queried, compared to those who did not. Cocaine, whether in powder or crack form, was positively associated with prostitution for both genders. A study showed that $90 \%$ of SWs use Iranian crack (24). In one study, the prevalence of HIV was $1.1 \%$, and chlamydia and gonorrhea $6.4 \%$. Moreover, the risk factors associated with infection were age and paying for sex (23). In our study, there was a significant relationship between age and receiving money for each sexual act.

In a study in Tunisia in 2010, Trichomonas infection was found in $72.9 \%$ of female SWs (25). In Madagascar, $7 \%$ of female SWs had trichomoniasis (26). In New Guinea, there was a $19 \%$ rate of trichomonas infections in female SWs (27). Syphilis was not observed in this study. It has been established that the presence of STDs increases the risk of HIV transmission. Hence, the results in SWs are different worldwide (28). In Papua New Guinea, Madagascar, and Mongolia, HIV infection was not observed in female SWs $(26,27,29)$.

In Kinshasa, Congo, HIV prevalence in female SWs was $12.4 \%$ (30). The results of this study suggest that multiple marriages are related to HIV and cervicitis. Multiple marriages, due to having more sex partners, can be the cause of this phenomenon. According to the AIDS progress report of the Ministry of Health and Medical Education, only $29.3 \%$ of injecting drug users and $7.9 \%$ of SWs in Iran had sufficient information about HIV (31). Although many of our study participants had some information about HIV, its spread, protection, and associated risk factors, their information was not enough and precise.

In Iranian traditional sexual norms, a woman has no role in her sex practice, which reduces her confidence in negotiating skills in condom use. Almost all participants believed that the majority of men refused to use a condom, and have a negative attitude towards it. Consequently, they do not use condoms regularly. Thus, it is a man's responsibility to protect the health of a woman, and refrain from having unprotected sex (32). Health education is necessary for men in Iran. It was demonstrated that there is a relationship between long-term adverse consequences of HIV, poverty, and drug abuse (33). In the present study, the role of poverty in the prevalence of HIV, drug use, and work for sex is obvious because their monthly income is 10 to 700 USD and the average is 201 USD.

Economic needs of female SWs have deprived them of the right to choose and the ability to use condoms, espe- 
cially when they earn more money for not using condoms. Other studies on the effects of power, poverty, and related communication skills showed that female SWs used condoms less than others (34). In this study, regular condom use had a significant correlation with educational level, cervicitis, and the number of sexual contacts per week. Substance abuse increases the rate of sex with multiple sexual partners (35). In our study, a significant relationship was observed between substance dependency and factors such as educational level, psychiatric drugs consumption, the number of sexual partners and sexual acts per week. Alcohol and drug abuse, and extramarital sex are forbidden in Islam; this may reduce addiction and the spread of HIV (36). In Iran, 90\% of female SWs have at least one type of personality disorder (37). Therefore, this factor should be considered in future studies. In this study, $45 \%$ of participants had a history of psychiatric drug use.

Hence, due to the subjective perception of a safe relationship in a temporary marriage, condom use should be suggested by either spouse. We should mention that fixed-term, temporary, and pleasure marriage are different names for the Arabic word of "Mut'a", which is a contract between a man and woman, much in the same way the long term/permanent/conventional marriage is. The main difference is that the temporary marriage lasts only for a specified period of time, and man and woman will become stranger to each other after the expiration date (38). Therefore, educational programs, aimed at a realistic understanding of susceptibility to risk of HIV, must be considered a strategic health priority (38). In the present study, the number of sexual partners reported by the participants was 1-10 per week, which is a high risk situation.

In general, to meet their specific needs for the injecting drug users, they should be given assistance and health services like training programs, access to protective supplies such as condoms, disposable syringes, free and regular HIV testing and STD diagnosis, and medicines to treat HIV and other diseases. Furthermore, treatment services such as obstetrics, prenatal care, social services, and mental health services by trained social care staff are also needed to treat injection drug users. In addition, it is of great importance to assure female SWs that they can have a decent living condition in Iran and other countries. This study did not investigate all factors associated with high risk sexual behaviors; therefore, it is recommended that more comprehensive studies be conducted for them and other SWs.

\section{Acknowledgements}

The authors would like to thank the personnel of the Medical Record Registry of Mazandaran University of Medical Sciences and Drop-in center for their utmost cooperation.

\section{Authors' Contributions}

Fatemeh Taghizadeh supervised all aspects of the study, including data analysis, and drafted the manuscript and revised it. Hassan Taghizadeh and Nasrin Shirdel supervised all field activities of the study and collected the clinical data. Mohammad Fathi provided information for the manuscript. Parisa Reihani and Seyede Mohaddese Rezaee conducted the statistical analyses and aided in the interpretation of analyses. All authors contributed to the final version of the manuscript and approved the final manuscript.

\section{Declaration of Interest}

None declared.

\section{References}

1. Quinn TC, Wawer MJ, Sewankambo N, Serwadda D, Li C, WabwireMangen F, et al. Viral load and heterosexual transmission of human immunodeficiency virus type 1. Rakai Project Study Group. N Engl J Med. 2000;342(13):921-9.

2. Cu-Uvin S, Hogan JW, Warren D, Klein RS, Peipert J, Schuman P, et al. Prevalence of lower genital tract infections among human immunodeficiency virus (HIV)-seropositive and high-risk HIVseronegative women. HIV Epidemiology Research Study Group. Clin Infect Dis. 1999;29(5):1145-50.

3. DeHovitz JA, Kelly P, Feldman J, Sierra MF, Clarke L, Bromberg J, et al. Sexually transmitted diseases, sexual behavior, and cocaine use in inner-city women. Am J Epidemiol. 1994;140(12):1125-34.

4. Fleming DT, Wasserheit JN. From epidemiological synergy to public health policy and practice: the contribution of other sexually transmitted diseases to sexual transmission of HIV infection. Sex Transm Infect. 1999;75(1):3-17.

5. Adimora AA, Schoenbach VJ, Martinson FE, Coyne-Beasley T, Doherty I, Stancil TR, et al. Heterosexually transmitted HIV infection among African Americans in North Carolina.J Acquir Immune Defic Syndr. 2006;41(5):616-23.

6. Rhodes TJ, Donoghoe MC, Hunter GM, Stimson GV. Continued risk behaviour among HIV positive drug injectors in London: implications for intervention. Addiction. 1993;88(11):1553-60.

7. Metsch LR, McCoy CB, Lai S, Miles C. Continuing risk behaviors among HIV-seropositive chronic drug users in Miami, Florida. AIDS and Behavior. 1998;2(2):161-9.

8. Des Jarlais DC, Perlis T, Arasteh K, Hagan H, Milliken J, Braine N, et al. "Informed altruism" and "partner restriction" in the reduction of HIV infection in injecting drug users entering detoxification treatment in New York City, 1990-2001. J Acquir Immune Defic Syndr. 2004;35(2):158-66.

9. Timpson SC, Williams ML, Bowen AM, Keel KB. Condom use behaviors in HIV-infected African American crack cocaine users. Subst Abus. 2003;24(4):211-20.

10. Sopheab H, Morineau G, Neal JJ, Saphonn V, Fylkesnes K. Sustained high prevalence of sexually transmitted infections among female sex workers in Cambodia: high turnover seriously challenges the $100 \%$ Condom Use Programme. BMC Infect Dis. 2008;8:167.

11. World Health Organization. Global prevalence and incidence of selected curable sexually transmitted infections.; 2001

12. Mondal NI, Hossain K, Islam R, Mian AB. Sexual behavior and sexually transmitted diseases in street-based female sex workers in Rajshahi City, Bangladesh. Braz J Infect Dis. 2008;12(4):287-92.

13. Folch C, Esteve A, Sanclemente C, Martro E, Lugo R, Molinos S, et al. Prevalence of human immunodeficiency virus, Chlamydia trachomatis, and Neisseria gonorrhoeae and risk factors for sexually transmitted infections among immigrant female sex workers in Catalonia, Spain. Sex Transm Dis. 2008;35(2):178-83.

14. Belza MJ, Spanish Group for the Unlinked Anonymous Survey of HIS. Prevalence of HIV, HTLV-I and HTLV-II among female sex workers in Spain, 2000-2001. Eur JEpidemiol. 2004;19(3):279-82.

15. Vall-Mayans M, Villa M, Saravanya M, Loureiro E, Merono M, Arellano E, et al. Sexually transmitted Chlamydia trachomatis, 


\section{Taghizadeh $\mathrm{H}$ et al.}

Neisseria gonorrhoeae, and HIV-1 infections in two at-risk populations in Barcelona: female street prostitutes and STI clinic attendees. Int J Infect Dis. 2007;11(2):115-22.

16. Mgone CS, Passey ME, Anang J, Peter W, Lupiwa T, Russell DM, et al. Human immunodeficiency virus and other sexually transmitted infections among female sex workers in two major cities in Papua New Guinea. Sex Transm Dis. 2002;29(5):265-70.

17. Rojanapithayakorn W. The 100 Per Cent Condom Use Programme A Success Story. Journal of Health Management. 2003;5(2):225-35.

18. Kazerooni PA, Motazedian N, Motamedifar M, Sayadi M, Sabet M Lari MA, et al. The prevalence of human immunodeficiency virus and sexually transmitted infections among female sex workers in Shiraz, South of Iran: by respondent-driven sampling. Int J STD AIDS. 2014;25(2):155-61.

19. Ahmadi K, Rezazade M, Nafarie M, Moazen B, Yarmohmmadi Vasel M, Assari S. Unprotected Sex with Injecting Drug Users among Iranian Female Sex Workers: Unhide HIV Risk Study. AIDS Res Treat. 2012;2012:651070.

20. Fahimfar N, Sedaghat A, Hatami H, Kamali K, Gooya M. Counseling and Harm Reduction Centers for Vulnerable Women to HIV] AIDS in Iran. Iran J Public Health. 2013;42(Supple1):98-104.

21. Sajadi L, Mirzazadeh A, Navadeh S, Osooli M, Khajehkazemi R, Gouya MM, et al. HIV prevalence and related risk behaviours among female sex workers in Iran: results of the national biobehavioural survey, 2010. Sex Transm Infect. 2013;89 Suppl 3:iii37-40.

22. Mirzazadeh A, Nedjat S, Navadeh S, Haghdoost A, Mansournia MA McFarland W, et al. HIV and related risk behaviors among female sex workers in Iran: bias-adjusted estimates from the 2010 National Bio-Behavoral Survey. AIDS Behav. 2014;18 Suppl 1:S19-24.

23. Platt L, Grenfell P, Bonell C, Creighton S, Wellings K, Parry J, et al. Risk of sexually transmitted infections and violence among indoor-working female sex workers in London: the effect of migration from Eastern Europe. Sex Transm Infect. 2011;87(5):377-84.

24. Maranda MJ, Han C, Rainone GA. Crack cocaine and sex. J Psychoactive Drugs. 2004;36(3):315-22.

25. Znazen A, Frikha-Gargouri O, Berrajah L, Bellalouna S, Hakim H, Gueddana N, et al. Sexually transmitted infections among female sex workers in Tunisia: high prevalence of Chlamydia trachomatis. Sex Transm Infect. 2010;86(7):500-5.

26. Harijaona V, Ramambason JD, Morisset R, Rasamindrakotroka A, Ravaoarinoro M. Prevalence of and risk factors for sexually-transmitted infections in hidden female sex workers. Med Mal Infect. 2009;39(12):909-13.

27. Gare J, Lupiwa T, Suarkia DL, Paniu MM, Wahasoka A, Nivia H, et al. High prevalence of sexually transmitted infections among female sex workers in the eastern highlands province of Papua New Guinea: correlates and recommendations. Sex Transm Dis. 2005;32(8):466-73.

28. Das A, Prabhakar P, Narayanan P, Neilsen G, Wi T, Kumta S, et al. Prevalence and assessment of clinical management of sexually transmitted infections among female sex workers in two cities of India. Infect Dis Obstet Gynecol. 2011;2011:494769.

29. Hagan JE, Dulmaa N. Risk factors and prevalence of HIV and sexually transmitted infections among low-income female commercial sex workers in Mongolia. Sex Transm Dis. 2007;34(2):83-7.

30. Vandepitte JM, Malele F, Kivuvu DM, Edidi S, Muwonga J, Lepira F, et al. HIV and other sexually transmitted infections among female sex workers in Kinshasa, Democratic Republic of Congo, in 2002. Sex Transm Dis. 2007;34(4):203-8.

31. Ministry of Health and Medical Education. Islamic Republic of Iran AIDS progress report. on monitoring of the united nations general assembly special session on HIV and AIDS..

32. Noar SM, Carlyle K, Cole C. Why communication is crucial: metaanalysis of the relationship between safer sexual communication and condom use. J Health Commun. 2006;11(4):365-90.

33. Semaan S, Lauby J, O'Connell AA, Cohen A. Factors associated with perceptions of, and decisional balance for, condom use with main partner among women at risk for HIV infection. Women Health. 2003;37(3):53-69.

34. Ehrhardt AA, Sawires S, McGovern T, Peacock D, Weston M. Gender, empowerment, and health: what is it? How does it work? J Acquir Immune Defic Syndr. 2009;51 Suppl 3:S96-S105.

35. Tross S, Hanner J, Hu MC, Pavlicova M, Campbell A, Nunes EV. Substance use and high risk sexual behaviors among women in psychosocial outpatient and methadone maintenance treatment programs. Am J Drug Alcohol Abuse. 2009;35(5):368-74.

36. Velayati AA, Bakayev V, Bahadori M, Tabatabaei SJ, Alaei A, Farahbood A, et al. Religious and cultural traits in HIV/AIDS epidemics in sub-Saharan Africa. Arch Iran Med. 2007;10 (4):486-97.

37. Ansari S, Gharraee B, Afsar-Kazerouni P. [Personality disorders and coping strategies in female sex-workers]. Iran J Psychiatry Clin Psychol. 2011;17(1):71-5.

38. Ahlul Bayt Digital Islamic Library Project A Shi'ite Encyclopedia. Available from: http://www.al-islam.org/shiite-encyclopedia-ahlul-bayt-dilp-team/temporary-marriage-islam-part-1. 